\title{
ÍNDICE DE ATENDIMENTO ESCOLAR: UM MODELO PARA AVALIAÇÃO COMPARATIVA ENTRE OFERTA E DEMANDA DE ESCOLAS DO ENSINO FUNDAMENTAL EM BELO HORIZONTE
}

Gabriel Luís Nogueira de Oliveira ${ }^{1}$

\begin{abstract}
Resumo: Serviços estatais oferecidos à população devem se sujeitar a análises mercadológicas para fins de avaliação da qualidade e eficiência. Assim como qualquer outro empreendimento, público ou privado, a educação pode se valer de ferramentas de Geomarketing para traçar suas estratégias. $\mathrm{O}$ objetivo deste trabalho é propor um modelo que visa avaliar a qualidade do atendimento escolar no município de Belo Horizonte para o ensino fundamental, para cada um dos seus três ciclos, parametrizado na comparação entre oferta e demanda. O modelo tem como resultado um índice que informa quais áreas do município estão mais ou menos bem atendidas pelo serviço, de acordo com critérios pré-estabelecidos.
\end{abstract}

Palavras-chave: Modelagem; Educação; Belo Horizonte.

\footnotetext{
${ }^{1}$ Bacharel em Geografia e mestrando em Análise e Modelagem de Sistemas Ambientais pela UFMG.
} 


\section{1- INTRODUÇÃo}

O Estado é uma instituição que remonta a antiguidade, quando sua formação trouxe aos primeiros povos sedentários e civilizados uma alternativa para resolução de conflitos e defesa de territórios (DIAMOND, 1997). A partir de então foi se adaptando conforme as relações sociais evoluíam, mas manteve por longo período sua essência primordial. Somente nos séculos XVIII que a noção do papel e legitimação do Estado viria a se transformar sob influência do Iluminismo.

Uma das mais notáveis contribuições do escopo teórico que legitimou o Estado Contemporâneo e suas atribuições veio de Jean-Jacques Rousseau, com a teoria do pacto (ou contrato) social. Segundo ele, o pacto social pressupõe processos que garantam privilégio ao âmbito coletivo para garantir a segurança do indivíduo (ROUSSEAU, 1757).

Vilalba expõe que "o problema do contrato social está em como fazer com que todos os homens vivam a liberdade e ao mesmo tempo abram mão de seus direitos em favor da liberdade coletiva e aceitem o pacto social" (VILALBA, 2013, p. 67). Justamente a partir desse e de outros questionamentos acerca da tradição estadista moderna que surgiram críticos de seu modelo. A importância do pensamento iluminista sobre o tema se deu na consolidação de ideias como direitos, democracia, liberdade, lei, entre outros. Em meados do século XIX Frédéric Bastiat2 já expunha: Há alguma classe ou alguém que ouse reinvindicar o direito de se colocar acima do povo, de decidir e agir por ele? “Não, não, o povo quer ser livre e o será. Ele quer dirigir seus próprios negócios e os dirigirá. Mas quando o legislador é finalmente eleito - ah! Então o tom do seu discurso muda radicalmente. O povo retorna à passividade, à inércia e à inconsciência”. (BASTIAT, 2010, p. 47).

Outros autores como Alexis de Tocqueville e, mais tardiamente, Ludwig von Mises e Friedrich Hayek, contribuíram para construção de uma corrente de pensamento hoje chamada de libertarianismo, marcada pelo constante questionamento ético e funcional do Estado.

\footnotetext{
${ }^{2}$ Bastiat foi um filósofo e economista francês do século XIX. Crítico inflexível da Revolução Francesa e do socialismo.
} 
O argumento ético de Franz Oppenheimer tornou-se célebre na tradição libertária:

Existem duas formas fundamentalmente opostas através das quais o homem, em necessidade, é impelido a obter os meios necessários para a satisfação dos seus desejos. São elas o trabalho e o furto, o próprio trabalho e a apropriação forçosa do trabalho dos outros. Eu proponho, na discussão que se segue, chamar ao trabalho próprio e à equivalente troca do trabalho próprio pelo trabalho dos outros, de "meio econômico" para a satisfação das necessidades enquanto a apropriação unilateral do trabalho dos outros será chamada de “meio político". O estado é a organização dos meios políticos. Como tal, nenhum estado pode existir enquanto os meios econômicos não criaram um definido número de objetos para a satisfação das necessidades, objetos que são passíveis de ser levados ou apropriados por roubo bélico. (OPPENHEIMER, 1926, p. 24-27).

A oposição às ideias estadistas modernas, de viés libertários ou não, não logrou êxito e passou longe da popularidade. Murray Rothbard postula em sua obra "A Anatomia do Estado" que em parte isso se deve a ampla aceitação do modelo de governo democrático. "Com o advento da democracia, a identificação do estado com a sociedade foi redobrada ao ponto de ser comum ouvir a vocalização de sentimentos que violam quase todos os princípios da razão e do senso comum, tais como: ‘nós somos o governo' ou 'nós somos o estado"' (ROTHBARD, 2012, p. 7). Os papéis dessa instituição cada vez mais sólida na sociedade contemporânea foram se ampliando. Dos primórdios, atuando como mediadora, ampliou-se para defesa territorial, cunhagem de moeda, legislação, e, nos dias atuais, interventora em uma lista de aspectos que tangem as relações sociais a todo tempo. Mises observou essa evolução na história e argumentou que "There is an inherent tendency in all governmental power to recognize no restraints on its operation and to extend the sphere of its dominion as much as possible" (MISES, p. 67, 2002). Em 1717, o então rei da Prússia, Frederico Guilherme I, decretou pela primeira vez na história obrigatório o ensino primário para crianças de 5 a 12 anos (ROTHBARD, 1999). A educação pública teve um de seus altos na história durante a Revolução Francesa, momento em que pessoas influentes defendiam enfaticamente o discurso, como Robespierre e Danton. "Foi somente durante a Revolução Francesa que se concretizaria, pela primeira vez a idéia de uma instituição pública e laica...” (Villela; 1990, p. 22). 
Com o passar do tempo os ideais da Revolução Francesa foram sendo difundidos e as áreas de atuação do Estado encontrando justificativa neles. Ao longo do século XX o estadismo foi ganhando força com a apologia ao Estado Provedor (Welfare State). Embora tenha raízes no socialismo fabiano e na social-democracia, foi consolidado com as teorias de John Maynard Keynes. Diversos países do globo foram gradativamente inserindo textos taxativos sobre a função educadora do Estado em suas constituições, até o ponto em que hoje pouco se questiona essa atuação, com exceção de focos de discordância libertárias.

\section{1- Educação no Brasil}

A educação brasileira tem origem ainda no período colonial, quando era papel da Companhia de Jesus levar ensino religioso e de pretexto civilizatório em território colonial. Ao longo do período Imperial, a educação pública foi marcado pela exclusão, visto que não importava à Coroa brasileira prover ensino à população em geral. Com a proclamação da República, em 1989, o ensino continuou excludente, mas, pouco a pouco, com o passar dos anos do século XX, a educação se tornou mais democrática e a atuação do Estado mais ativa. A Constituição de 1988 traz a seguinte concepção sobre as designações do Estado no que diz respeito à educação pública:

“Art. 205. A educação, direito de todos e dever do Estado e da família, será promovida e incentivada com a colaboração da sociedade, visando ao pleno desenvolvimento da pessoa, seu preparo para o exercício da cidadania e sua qualificação para o trabalho.

Art. 206. O ensino será ministrado com base nos seguintes princípios: I igualdade de condições para o acesso e permanência na escola; (...) III pluralismo de idéias e de concepções pedagógicas, e coexistência de instituições públicas e privadas de ensino; IV - gratuidade do ensino público em estabelecimentos oficiais; (...) VI - gestão democrática do ensino público, na forma da lei;" (BRASIL, CF, 1988).

Também consta que cabe à esfera municipal atuar prioritariamente no ensino fundamental e da educação infantil (BRASIL, CF, 1988, art. 211). A educação pública municipal de Belo Horizonte é parte do objeto de estudo deste trabalho, conforme descreve o subitem seguinte. 


\section{2- Problematização e Objetivos}

O município de Belo Horizonte oferta em seu território escolas municipais que contemplam a educação infantil, ensino fundamental e educação de jovens e adultos (EJA). O ensino fundamental é dividido em três ciclos. Assim como todo serviço ofertado pelo Estado, a educação não foge à lógica das relações de oferta e demanda. Pensa-se que esse tipo de raciocínio cabe somente à esfera privada quando esta empreende. Contudo, a gestão pública se torna menos ineficiente quando assume uma visão mercadológica do problema. Garantir acesso às escolas é um desafio e intenção de todo governo, e, para isso, recorre à análises para embasar seu planejamento.

A questão fundamental aqui não é acerca da qualidade de ensino ou infraestrutura das escolas, mas é sobre onde elas estão localizadas no território e como isso afeta o acesso por parte dos alunos. Afinal, existem escolas onde existem altas demandas? E essas escolas disponibilizam vagas suficientes? Onde está a "clientela" do município? Como avaliar espacialmente o acesso às escolas no território municipal? Acredita-se que com a metodologia deste artigo é possível criar um índice comparativo de áreas que relaciona a oferta e demanda pelo ensino fundamental. Em outras palavras, é possível saber quais áreas estão mais ou menos bem atendidas pela rede municipal de educação para o ensino fundamental. Objetiva-se, portanto, estimar valores comparativos que correspondem ao Índice de Atendimento Escolar.

Deve-se ter em mente a responsabilidade da administração pública quando oferece qualquer serviço. Relembrando as palavras de Oppenheimer (1926), o Estado existe em função da apropriação forçada do trabalho. Se isso já é tido por muitos como argumento ético suficiente, quando o Estado arrecada e não disponibiliza universalmente e com qualidade, sob uma ótica utilitária, ele não possui justificativas para arrecadar. Bastiat argumenta que "ao criar monopólio ${ }^{3}$ da educação, o governo deuse a obrigação de corresponder às esperanças dos pais de famílias, que foram privados então de sua liberdade. E se essas esperanças não foram correspondidas, de quem é a culpa?” (BASTIAT, 2010, p. 51). Argumentos utilitários relevantes podem ser encontrados nas obras de vários autores, comoo argumento da ineficiência. Tudo que é gerido pelo governo não precisa se sujeitar ao mecanismo de lucros e prejuízos. Logo, qual o incentivo para ser eficiente se, quando algo dá errado, o Tesouro arca com os custos? (MISES, 2009).

\footnotetext{
${ }^{3}$ Apesar da educação no Brasil não se caracterizar um serviço monopolizado pelo Estado, como o serviço postal, as inúmeras diretrizes e regulamentações do setor atuam atrofiando a qualidade e encarecendo a educação privada no país.
}

Cadernos do Leste

Artigos Científicos

Belo Horizonte, Jan.-Dez. Vol.17, n¹7, 2017 
Acredita-se que é possível analisar o objeto de estudo utilizando ferramentas empregadas em Geomarketing. Geomarketing é uma abordagem que considera a espacilialidade de fenômenos como componente essencial na tomada de decisões envolvendo gestão de negócios. Pode ser aplicado a uma vasta gama de situações, inclusive para tornar as ações governamentais mais efetivas. Desde uma simples visualização de variáveis até aplicação de modelos mais complexos podem auxiliar um gestor a dignosticar aspectos mercadológicos ou tomar decisões. Masano (2003) afirma que a localização é um fator determinante sobre o sucesso ou fracasso de um empreendimento. No presente estudo, modelos de geoestatística foram empregados para construção de um modelo maior que fornece o Índice de Atendimento Escolar para cada ciclo do ensino fundamental da rede pública de Belo Horizonte, baseado na localização das escolas e na localização dos potenciais consumidores.

\section{2- PROCEDIMENTOS METODOLÓGICOS}

Neste item serão explicados as etapas através das quais o modelo de estimação do nível de atendimento à população foi construído e executado. No entanto, antes de adentrar propriamente nos procedimentos, o subitem seguinte aborda as premissas norteadoras da metodologia.

\section{1- Variáveis do Modelo}

Um dos objetivos desse modelo é trabalhar com noções básicas que estão diretamente relacionadas ao atendimento de uma população no que se refere a serviços públicos. Sendo assim, apenas três variáveis foram escolhidas para compor a equação que calcula o índice que servirá de indicador para o que se busca avaliar. Embora qualquer serviço possa ser avaliado em diversos aspectos, como qualidade profissional ou nível tecnológico, escolheu-se analisar um aspecto fundamental na gestão de oferta: a espacialidade do serviço ofertado.

Para qualquer empreendimento é necessário um planejamento que vise otimizar a relação entre os consumidores e o ponto onde ele terá suas demandas supridas. Para o caso da rede municipal de educação, em um modelo ideal, em nenhuma área ${ }^{4}$ de Belo Horizonte se encontraria alguma dessas características: residentes que tenham que cobrir grandes distâncias a pé para escola;

\footnotetext{
4 O termo "área" é empregado diversas vezes no texto pois a unidade espacial de análise não corresponde à nenhuma divisão administrativa como bairros ou setores censitários.
} 
baixa oferta de vagas das escolas mais próxima (que acarreta no primeiro problema citado); excesso de vagas ofertadas pelas escolas mais próximas, ou seja, má gestão de recurso público.

Tendo em vista esse cenário ideal, levanta-se a seguinte questão: como estimar a relação entre as vagas que são ofertadas e demandadas por áreas da cidade? Antes de relacionar as variáveis envolvidas no problema, há de se identificá-las para compor o modelo:

I) Oferta: em essência é quantidade de vagas que a prefeitura oferece. Porém, como está sendo posto em análise o fator da espacialidade, não basta saber o total de vagas que ela dispõe no território municipal como um todo. As coordenadas de cada escola e a quantidade de vagas que cada uma delas dispõe individualmente compõem de maneira sintética a variável oferta. No subitem seguinte será explicado como a oferta é uma grandeza espacialmente detectável e quantificável, passível de ser utilizada em operações matemáticas.

II) Demanda: esta variável tem a sua espacialidade ainda mais explícita. Diz respeito às coordenadas das residências da população alvo da educação de nível fundamental. Para cada área de Belo Horizonte, reside uma quantidade/densidade distinta de crianças e adolescentes, que refletem o perfil demográfico de cada uma delas.

III) Distância: é simplesmente a distância em linha reta (euclidiana) entre a coordenada das residências (demanda) em relação à escola mais próxima (oferta). Ela é um aspecto importante no modelo ao se considerar o seguinte cenário: algumas áreas podem demandar poucas vagas, e as escolas mais próximas podem ofertar mais do que precisam. Contudo, quanto maior for a distância até a escola mais próxima, maior a influência negativa da variável no índice final, fazendo com que o cenário que parecia ser positivo não seja tão positivo assim.

\section{2- Cálculo do Índice de Atendimento Escolar}

Como foi explanado no item anterior, o objetivo do modelo é criar um índice que revele, comparativamente, áreas que são mais ou menos bem atendidas pelo serviço municipal de educação, para cada um dos três ciclos do ensino fundamental.

A equação utilizada para seu cálculo deve representar nas funções matemáticas, de maneira simples e intuitiva, a relação existente entre as variáveis. Oferta e demanda se relacionam diretamente. É lógico pensar que quanto maior for a demanda em relação à oferta, pior deverá ser o indicador, assim como o cenário oposto também é válido. O modelo expressa essa lógica matematicamente utilizando a divisão, ou seja, uma razão entre as variáveis (para $x$ vagas existem $y$ potenciais 
estudantes). A distância entra por último para refinar o indicador. A essa razão multiplica-se a distância, de tal forma que quanto maior ela for, mais reduzirá o valor do índice.

$$
\text { Índice }=\frac{\text { Oferta }}{\text { Demanda }} \times \text { Distância }
$$

Para executar essa função, foi escolhido o método de operações matriciais. Cada uma das variáveis foi transformada em um mapa de caráter matricial, cujas células portam os respectivos valores. Nos três subitens a seguir estão descritos os procedimentos para a construção das matrizes

\section{3- Mapa de Oferta}

A confecção do mapa de oferta requer dois dados: as coordenadas de todas as escolas de nível fundamental da rede municipal de Belo Horizonte e quantas vagas elas dispõem por ciclo. Ambas os dados foram adquiridos mediante consulta com a Secretaria Municipal de Educação. Uma vez em mãos a lista com todas as escolas que oferecem ensino fundamental e seus respectivos endereços, foram todas georreferenciadas em forma de pontos através do software Google Earth. O arquivo. $\mathrm{kml}$ foi convertido para .shp para ser trabalhado no ambiente do software ArcGIS. Através dele foram inseridos na tabela de atributos do vetor três colunas, referentes aos ciclos do ensino fundamental. Com outra tabela disponibilizada pela Secretaria, foram acrescentada as vagas. Nem todas as escolas oferecem três ciclos; algumas possuem apenas um. Para cada ciclo foi exportado um vetor novo, identificado pelos atributos quando o valor era maior que zero. As escolas que possuem valor zero para vagas de algum ciclo foram excluídas do vetor do respectivo ciclo. O resultado desse processo foram três arquivos .shp de pontos.

As coordenadas das escolas e suas vagas ofertadas serviram para executar um modelo de densidade de pontos chamado de Kernel para cada um dos ciclos. Em estatística, a estimativa de densidade Kernel é um método de estimara função de densidade de probabilidade de uma variável aleatória, resultando numa suavização de dados que inferem sobre uma população. (SILVERMAN, 1998). O modelo pode ser executado no ambiente do ArcGIS. O valor utilizado para o raio de influência, parâmetro básico do estimador, foi de 3000 metros para o primeiro e segundo ciclos, e de 4000 para o terceiro. A densidade foi ponderada pelo número de vagas ofertada pelas escolas. Por fim, foi necessário normalizar os valores obtidos pela função de densidade Kernel para reduzir a 
dispersão dos dados. A função é bastante simples: os valores de densidade foram classificados em intervalos de $1 / 4$ de desvio padrão. Para cada uma das classes foram atribuidos ordinalmente valores de 1 até a última delas. Essa normalização não modifica a essência dos dados de densidade, apenas reduz a quantidade de valores únicos e a variância interna da amostra. Em suma, é uma representação da oferta em forma de níveis ao longo do território municipal, e não um valor de oferta real para cada pixel da matriz.

\section{4- Mapa de Demanda}

A base de dados fundamental dessa etapa é o Censo Demográfico do IBGE de 2010. O órgão dispõe de forma online os resultados completos do censo. Além de possuir dados sobre população, é possível filtra-los por setor censitário, que são polígonos que, de um forma geral, possuem um tamanho ótimo para o procedimento realizado na etapa de estimação da demanda.

Os dados do município de Belo Horizonte foram separados do restante dos outros municípios de Minas Gerais e as variáveis de interesse também. O censo informa características íntrinsecas à população consultada no ano de 2010. O ano de interesse neste estudo é 2017, portanto foi necessário fazer adaptações nos dados. Para cada setor censitário existe um conjunto de variáveis que informam a quantidade de crianças por idade (V001 à V019 da planilha Pessoas07_UF.xls). Os ciclos escolares do ensino fundamental abragem as seguintes faixas etárias: de 6 a 8 anos para o primeiro ciclo; de 9 a 11 para o segundo; 12 a 15 para o terceiro. Sendo assim, para identificar esses intervalos para o ano de 2017 bastava que fossem encontradas as idades atuais menos sete anos de diferença. As crianças que em 2010 tinham 1 ano, hoje estão com 8 e, portanto, entram para o grupo do primeiro ciclo. Para encontrar a quantidade de crianças que hoje estão com 6 anos, utilizou-se a quantidade de mulheres grávidas ${ }^{5}$ em Belo Horizonte e aplicou-se uma regra de trê para dividir o número entre os setores, com base na quantidade total de crianças. Logicamente que este processo ignora possíveis trocas de residências que aconteceram entre 2010 e 2017, porém parte do pressuposto de que capta a essência do perfil demográfico dos setores censitários. Os números de potenciais estudantes de cada ciclo por setor censitário foram incorporados à tabela de atributos do shapefile de setores de Belo Horizonte. Os polígonos foram convertidos para pontos através da função Features to Points ${ }^{6}$, do software ArcGIS. O intuito é usar os pontos para criar uma superfície

\footnotetext{
${ }^{5}$ Dado fornecido pelo Sistema de Informação da Atenção Básica (SIAB) do Ministério da Saúde.

${ }^{6}$ A função utiliza o centróide do polígono para transformar a feição em ponto.
} 
interpolada cujos valores servirão de indicador de demanda para cada um dos ciclos. O método de interpolação escolhido é o IDW (Inverso da Distância Ponderada). Segundo Setianto e Triandini (2013), o modelo de IDW considera que a taxa de correlação e as similaridades entre os vizinhos são proporcionais à distância entre eles, e os pontos estimados são resultado de como as correlações declinam à medida que se distancia dos pontos da amostra. O raio utilizado é fixo com valor de 1000 metros para todos os ciclos.

Assim como no subitem anterior, os dados precisaram ser normalizados. O mesmo procedimento de classificação foi adotado, e aos intervalos definidos por $1 / 4$ de desvio padrão foram atribuídos valores de 1 a o último.

\section{5- Mapa de Distâncias}

Utilizando o shapefile com as coordenadas das escolas calculou-se um mapa de distâncias através da função Euclidean Distance, do ArcGIS. Ela cria uma matriz em que os pixels são valorados com a distância até o ponto mais próximo em linha reta ${ }^{7}$. A distância euclidiana é calculada com base no teorema de Pitágoras, em que pontos hipotéticos A e B são ligados por uma linha que corresponde à hipotenusa de um triângulo retângulo.

A normalização dos valores de distância, que foram dados em metros, foi feita através da seguinte equação inserida na função Raster Calculator.

$$
z=1-\frac{x-\min (x)}{\operatorname{má} x(x)-\min (x)}
$$

Em que: z corresponde ao valor normalizado; x é o valor do píxel; min(x) é o menor valor observado e $\max (\mathrm{x})$ o maior valor observado. A fórmula faz com que os pixels adquiram valores entre 0 e 1 , mantendo as proporções originais. O valor é subtraído de 1 para que a normalização seja invertida, ou seja, as maiores distâncias ficarão mais próximas de 0 , e as menores distâncias mais próximas de 1. A justificativa é justamente fazer com que, quando multiplicada a relação de oferta e demanda pelo mapa de distâncias, os menores valores (que após a normalização correspondem às maiores distâncias) tornem o índice menos positivo. O índice do todos os pixels serão diminuídos após multiplicados pela distância, com exceção de um único pixel que possui valor 1 no mapa de distância.

\footnotetext{
${ }^{7}$ Em um modelo mais acurado, poderia-se calcular as distâncias com base na rede viária.
} 


\section{6- Aplicando o cálculo de matrizes}

Após obter as matrizes a função Raster Calculator foi acionada para executar a equação descrita no subitem 2.2. A figura 2 mostra o exemplo do primeiro ciclo, com seus mapas correspondentes às variáveis e a equação que as relaciona.

Finalmente, tendo gerado o raster que corresponde ao Índice de Atendimento Escolar, foram excluídos pixels de áreas não urbanizadas ou que não possuem ocupação residencial. Primeiramente a máscara utilizada para excluí-los equivale às áreas do Campus da UFMG, o Museu de História Natural da UFMG, a Lagoa da Pampulha e o aeroporto. Com auxílio do shapefile de áreas urbanizadas, disponibilizado pelo IBGE, foram eliminados os pixels restantes ${ }^{8}$.
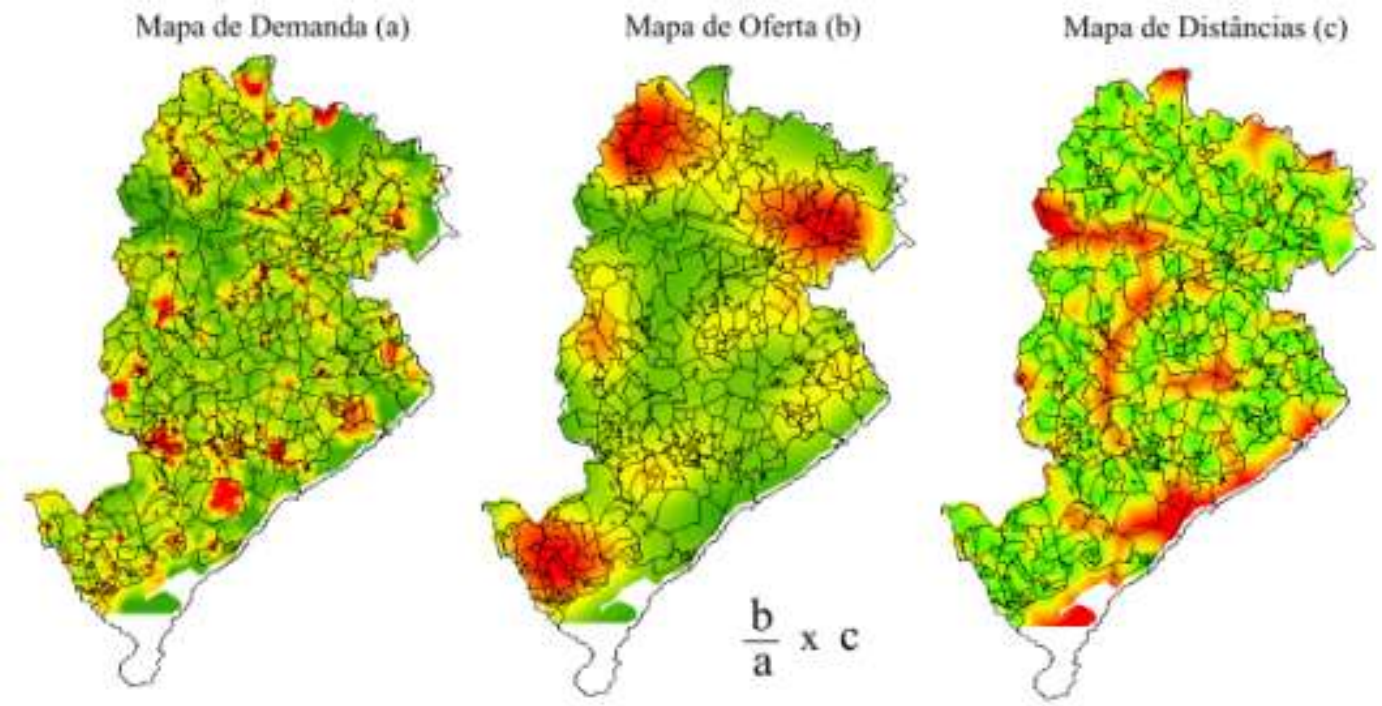

Fig. 2 - Matrizes do Primeiro Ciclo

\section{2- RESULTADOS E DISCUSSÕES}

Antes de apresentar os mapas com os resultados, é importante frisar que o Índice de Atendimento Escolar de cada ciclo não pode ser comparado eles. Ou seja, um determinado valor de índice pode ser enquadrado como elevado em uma análise, mas nem tanto em outra. Pelo fator da normalização utilizar o maior e menor valor observado em cada análise, sem definição apriori do que são valores muito ou pouco consideráveis, o Índice só pode ser comparado entre as áreas para um

\footnotetext{
${ }^{8}$ O resultado do uso dessa máscara foi a eliminação de: diversas áreas ao longo da serra, que vai da borda região Leste até a borda do Barreiro; diversas áreas na região Nordeste e Venda Nova, na fronteira com o município de Santa Luzia.
} 
mesmo ciclo escolar. É justamente este o propósito: aferir, por meio de comparações entre áreas, aquelas que são mais ou menos bem atendidas por cada ciclo do ensino fundamental. A figura 3 exibe os resultados para o primeiro ciclo. Analisando a distribuição de cores no mapa, nota-se uma aparente forte influência da variável oferta no resultado final. Venda Nova, Nordeste e Barreiro são regiões com alta densidade de escolas e vagas, o que culminou em índices mais elevados, mesmo sendo focos de demanda consideráveis.

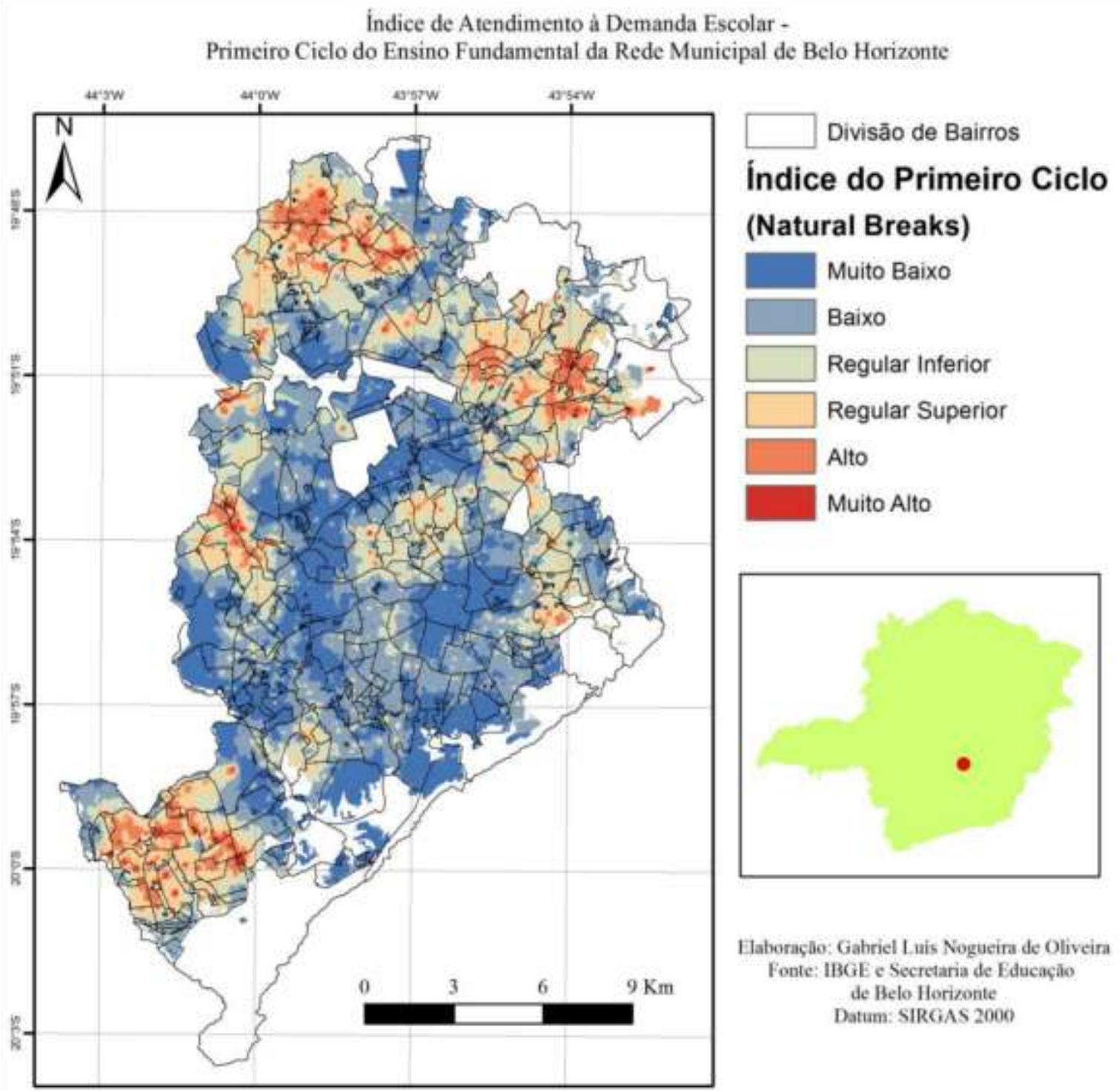

Fig. 3 - Mapa com os resultados do Índice de Atendimento Escolar do primeiro ciclo

Contudo, a sobreposição da variável oferta com o resultado final está longe de ser perfeita. Na própria região de Venda Nova, alguns pixels com alto valor de demanda fizeram o Índice ficar 
mais baixo que o esperado, prevalecendo sobre a alta oferta. Essa áreas apresentam, portanto, um perfil demográfico que requer um atendimento escolar mais presente.

A regiões noroeste e oeste de Belo Horizonte possuem um vazio de escolas que forma uma feição no mapa parecida com um corredor. Mesmo com pouco focos de procura, a área apresentaou índices bastante negativos. A região centro-sul, por sua vez, também possui baixos índices, mas provavelmente por não ser inclusa na estratégia de atendimento da prefeitura. Seu perfil demográfico é, em geral, de rendas maiores, e potencialmente consumidoras de serviço privado de educação, sendo essa uma variável promissora para modelos mas acurados sobre o assunto, em possíveis novas análises. Porém, tendo em vista que o serviço público de educação busca fornecer um serviço de qualidade sem distinção social e que todas as famílias pagam por ele, áreas como a região centro-sul não deveriam ser negligenciadas. 


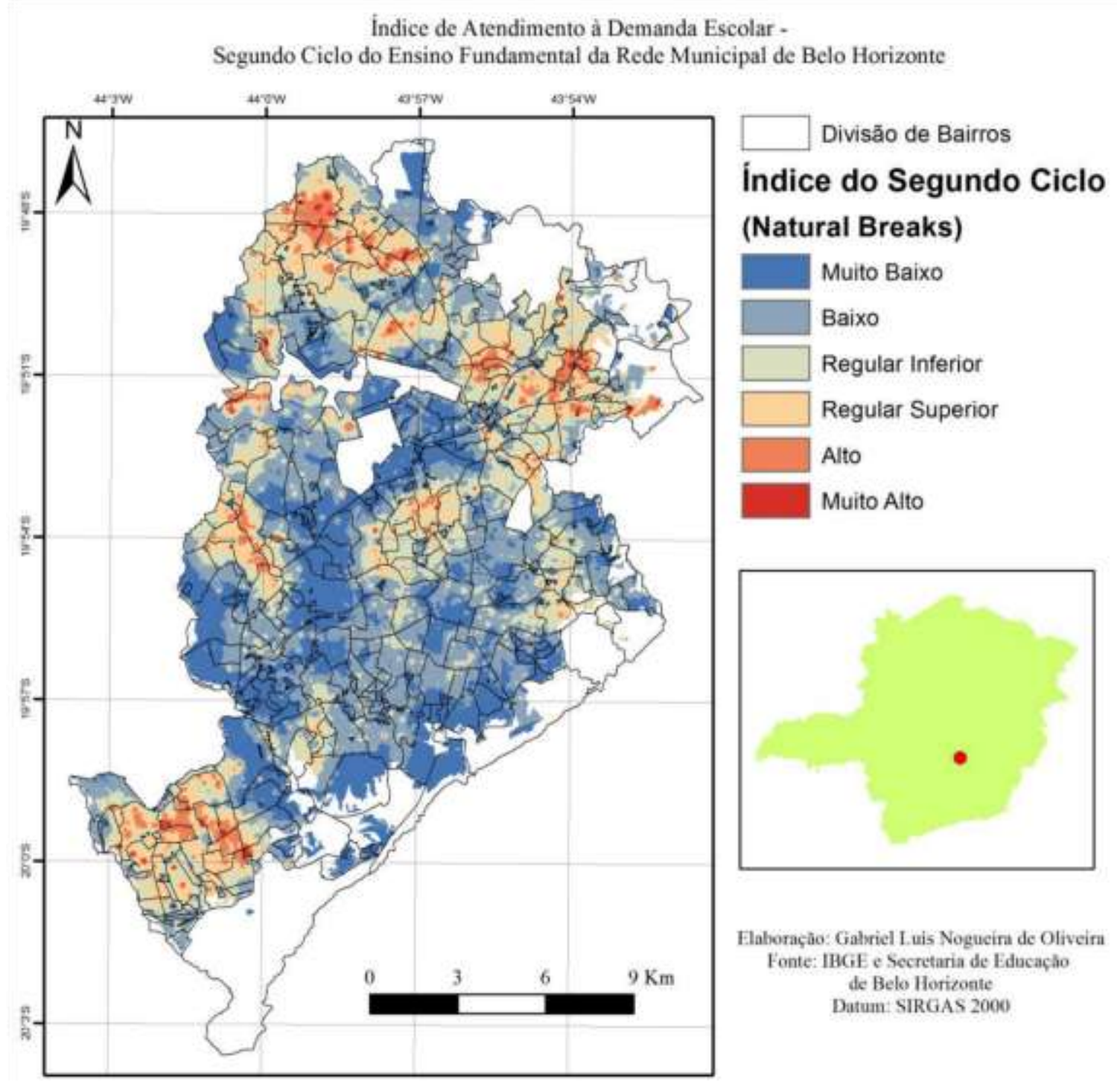

Fig. 4 - Mapa com os resultados do Índice de Atendimento Escolar do segundo ciclo

As feições dos mapas dos índices do primeiro e segundo ciclo (figura 4) são bastante similares. A explicação é bastante simples. A diferença entre a quantidade de crianças de 6 a 8 anos e a de crianças de 9 a 11 por setor censitário é bem pequena. Os mapas de demanda mostraram as mesmas características demográficas. Somente o terceiro ciclo que apresentou uma configuração de demanda um pouco mais distante em relação ao primeiro. A outra razão é que a interseção entre as escolas de primeiro e segundo ciclo é grande.

No mapa a seguir, com os resultados do terceiro ciclo, as feições já se distanciam mais, embora ainda se perceba uma tendência geral. A região centro-sul neste caso já é mais bem atendida, 
provavelmente por uma questão de estratégia: alunos mais velhos podem sair dos focos de demandas em áreas mais periféricas e se deslocar maiores distâncias até o centro.

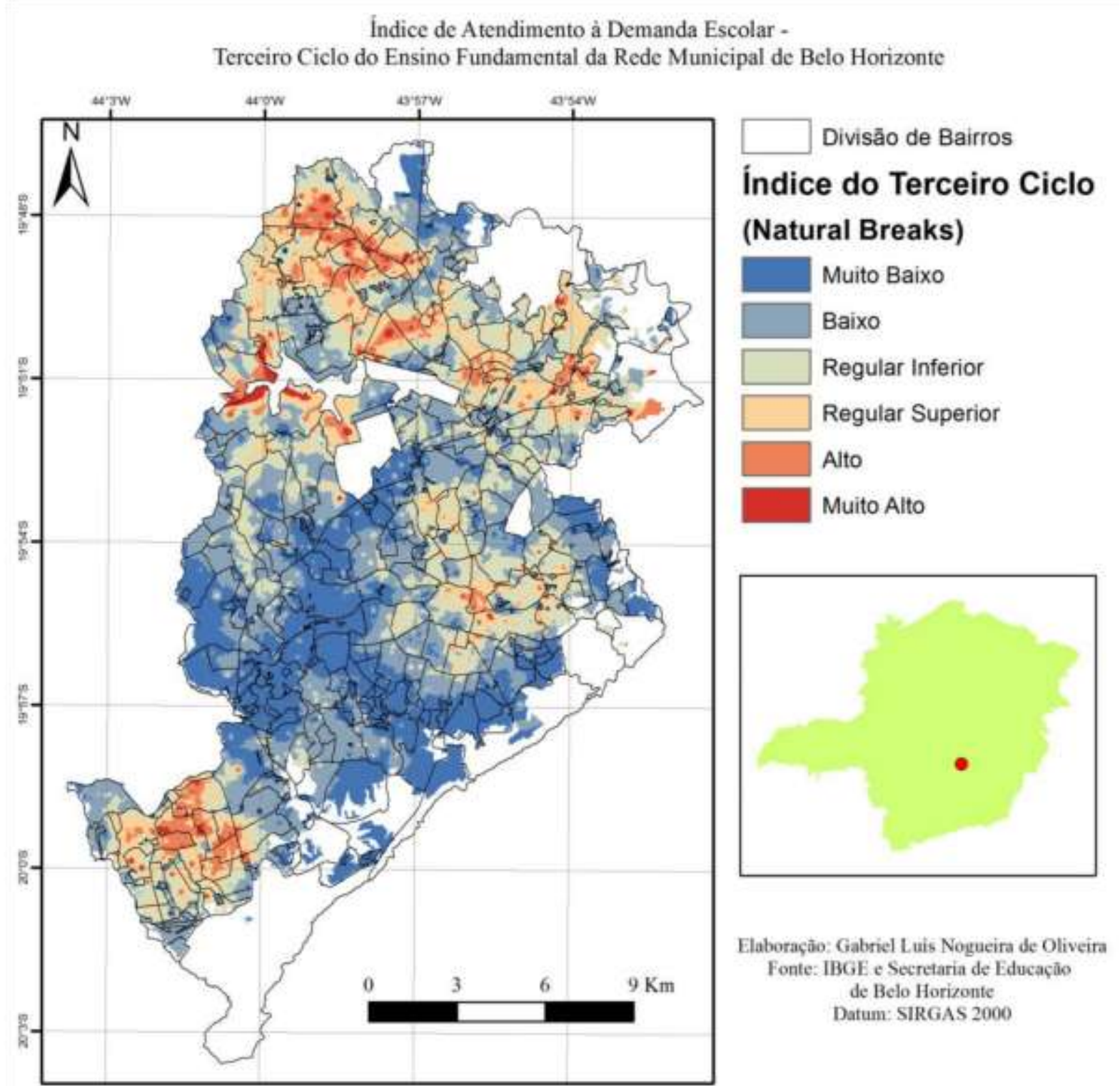

Fig. 5 - Mapa com os resultados do Índice de Atendimento Escolar do terceiro ciclo

Um último mapa foi calculado, contendo a média dos três mapas anteriores, obtida através da função Raster Calculator. Serve para sintetizar o Índice de Atendimento Escolar para todo o ensino fundamental da rede municipal de Belo Horizonte. Calculando-se o média dos pixels de cada bairro, tem-se os valores para os seguintes bairros destacados: 


\begin{tabular}{ccc} 
Posição & Nome do Bairro & Média \\
\hline Primeiro & Guanabara & 3.727 \\
Primeiro do Quartil 3/4 & Nova América & 1.236 \\
Primeiro do Quartil 2/4 & Juliana & 0.839 \\
Primeiro do Quartil 1/4 & Vila Paris & 0.560 \\
Último & Acaba Mundo & 0.085 \\
& Geral & 0.920 \\
\hline
\end{tabular}

Tabela 1 - Média do Índice por bairro

\section{2- CONSIDERAÇÕES FINAIS}

Ao longo das últimas décadas diversos autores têm se empenhado em demonstrar a ineficiência administrativa do governo em vários de seus campos de atuação. A educação pública tem como foco de críticas a qualidade do ensino, pois os alunos da rede pública de uma forma geral tem obtido resultados ruins em exames e indicadores de desempenho escolar. Atentando-se para o aspecto alvo deste estudo, é possível afirmar que, em Belo Horizonte, as últimas gestões não têm feito um trabalho exemplar na localização de oferta de vagas para o ensino fundamental no território municipal. Isso se mostra evidente em função do grande desvio padrão apresentado pelo índice, que revela uma desigualdade espacial da oferta em relação à demanda entre as áreas.

É importante ressaltar que as últimas políticas de espraiamento da oferta, levando escolas para áreas mais periféricas, galgou importantes conquistas no atendimento de regiões como Venda Nova, Barreiro e Nordeste. Todavia, partindo novamente do pressuposto de Oppenheimer, se o governo espolia e a lei assegura acesso livre e de qualidade à educação, o fator renda não deveria ser considerado nos critérios de localização de vagas. Mesmo se alguém argumentasse que é justo que a educação pública tenha foco em famílias financeiramente desfavorecidas, haveria de se questionar o fato dos bairros em Belo Horizonte não serem perfeitamente homogêneos internamente. Em outras palavras, há estudantes de baixa renda em regiões tidas como de alta tendo de se deslocar grandes distâncias por causa da política de foco de atendimento. Por fim, é necessário nivelar a oferta de vagas em razão da demanda existente em cada local, de modo a diminuir a disparidade do índice no território de Belo Horizonte. 
Acerca do modelo, tem como ponto forte sua reaplicabilidade garantida por sua simplicidade. No entanto, poderia ser mais assertivo se incorporasse outras variáveis relevantes que não comprometem sua reaplicabilidade.

\section{REFERÊNCIAS BIBLIOGRÁFICAS}

BASTIAT, F. A lei. $3^{a}$ edição. São Paulo: Instituto Ludwig von Mises Brasil, 2010. 62 p.

BRASIL, Artigo 205, Constituição Federal, 1988.

BRASIL, Artigo 206, Constituição Federal, 1988.

BRASIL, Artigo 211, Constituição Federal, 1988.

DIAMOND, J. Armas, germes e aço. 15ª edição. Rio de Janeiro: Record, 2013. 317 p.

MASANO, Tadeu Francisco. Geografia de mercado. In: MASANO, Tadeu Francisco et al. Gestão

de marketing. Escola de Administração de Empresas de São Paulo - Fundação Getúlio Vargas. São

Paulo: Saraiva, 2003. p. 167- 213.

MISES, L. As seis lições. $7^{\mathrm{a}}$ edição. São Paulo: Instituto Ludwig von Mises Brasil, 2009. 106 p.

Liberalism in the Classical Tradition. $3^{\mathrm{a}}$ edição. San Francisco: Cobden Press, 2002. 201 p.

OPPENHEIMER, F. The State. New York: Vanguard Press, 1926.

ROTHBARD, M. A anatomia do Estado. 1a edição. São Paulo: Instituto Ludwig von Mises Brasil, 2012. 50 p.

. Education: free and compulsory. Auburn: Ludwig von Mises Institute, 1999.

ROUSSEAU, J-J. O contrato social. In: Oeuvres completes, tome III. Collection "Pléíade". Paris: Gallimard, 1757.

SETIANTO, A; TRIANDINI, T. Comparison of kriging and inverse distance weighted (idw) interpolation methods in lineament extraction and analysis. Journal of Southeast Asian Applied Geology, Yogyakarta, v. 5, n. 1, p. 21-29, 2013.

SILVERMAN, B. W. Density Estimation for Statistics and Data Analysis. London: Chapman \& Hall/CRC, 1998. 
VILALBA, H. G. O contrato social de Jean-Jacques Rousseau: uma análise para além dos conceitos. Filogênese, Marília, v. 6, n. 2, p. 63-76, 2013.

VILLELA, H. O. S. A primeira escola normal do Brasil: uma contribuição à história da formação de professores. Dissertação de Mestrado, Faculdade de Educação, Universidade Federal Fluminense, Niterói, 1990. 